\title{
Health Insurance Reforms and Health Policies in Rural China
}

Martine Audibert, Xiaoxian Huang, Xiezhe Huangfu, Jacky Mathonnat, Aurore Pélissier and Laurène Petitfour

Translator. Jonathan Hall

\section{OpenEdition}

\section{Journals}

\section{Electronic version}

URL: http://journals.openedition.org/chinaperspectives/7098

DOI: 10.4000/chinaperspectives.7098

ISSN: 1996-4617

Publisher

Centre d'étude français sur la Chine contemporaine

\section{Printed version}

Date of publication: 1 December 2016

Number of pages: 29-38

ISSN: 2070-3449

Electronic reference

Martine Audibert, Xiaoxian Huang, Xiezhe Huangfu, Jacky Mathonnat, Aurore Pélissier and Laurène Petitfour, "Health Insurance Reforms and Health Policies in Rural China », China Perspectives [Online], 2016/4 | 2016, Online since 01 December 2017, connection on 14 November 2019. URL : http:// journals.openedition.org/chinaperspectives/7098; DOI : 10.4000/chinaperspectives.7098 


\title{
Health Insurance Reforms and
}

\section{Health Policies in Rural China}

\author{
MARTINE AUDIBERT, XIAOXIAN, HUANG, XIEZHE HUANGFU, \\ JACKY MATHONNAT, AURORE PÉLISSIER, AND LAURENE PETITFOUR
}

\begin{abstract}
Since the early 2000s, the Chinese government has undertaken a series of reforms in the health sector. Among these, the three most important have been concerned with medical insurance, hospital administration, and pharmaceutical policies. The aims of these reforms were to extend health insurance coverage, to increase the activities and the efficiency of the health establishments, and to improve patient care. This article focuses on two components of these reforms: the development of health insurance in rural areas and the policy on essential medicines in conjunction with hospital reforms. Our longstanding co-operation with a research team from Weifang University and with the Weifang Health Bureau allowed us to follow these reforms and collect data (primary source) from a sample of township hospitals from Weifang Prefecture. Those data allowed us to study their effects on health facilities' level of activity and efficiency. This article provides an overview of studies we carried out on these issues over the period from 2000 to 2012. Our analyses were mainly based on non-parametric models (Data Envelopment Analysis, Malmquist Index, and partial frontiers) and impact analyses, coupled with interviews with hospital staff and medical authorities. Results show that the development of health insurance in rural areas had a positive effect in greatly increasing the activities of the hospitals covered by our study. On the other hand, it did not have a positive influence on their efficiency, which declined in the period concerned. This result is to be explained by the fact that, even though staff activity increased, it remained low, since the observed increase in activity was not sufficient to make up for the parallel increase in staff numbers. Similarly, reforms in the hospital and pharmaceutical sectors had no effect on the township hospitals of our survey. In fact, in order to compensate for the observed reduction of hospital resources following the introduction of the reforms, on the one hand the government increased the subsidies allocated to township hospitals, and on the other hand the hospitals strongly innovated in sophisticated and expensive care, to the benefit of a relatively small number of patients. Therefore, there were some very positive steps forward, but they still call for a more nuanced assessment of the effects of the reforms.
\end{abstract}

KEYWORDS: Technical efficiency, non-parametric approach, Malmquist Index, township hospitals, health insurance, hospital and pharmaceutical reforms, China, Weifang Prefecture.

T he economic opening of China that Deng Xiaoping called for in the late 1970s contributed to strong and sustained economic growth (the average increase in GDP approached a regular $10 \%$ annually between 1980 and $\left.2014^{(1)}\right)$, allowing a quadrupling of income per capita from 1990 to 2006, and a doubling between 2006 and 2014. This rate of income growth was accompanied by a spectacular reduction in poverty and an overall improvement in health, which was nonetheless not as marked as in the Maoist period when progress had been very impressive. For example, life expectancy at birth rose from 35 to 65 years between 1949 and 1975, but "only" rose from 67 to 75 years between 1981 and 2014. Over the latter period, other countries performed better, with lower rates of GDP growth. These developments were however accompanied by large increases in social inequality. In the field of health provision, the rural population's access to care came up against a real financial barrier right from the early years of the establishment of "market socialism."

In the 1960s, the poor health of the rural population and the bias towards the cities to the detriment of the rural areas led the government to launch a huge healthcare programme based on the short-term training of "barefoot doctors" and the establishment of rural medical co-operative programmes.
The nationwide emphasis on basic healthcare enabled China, with its essentially rural population ( $74 \%$ in 1990 (2)), to obtain health indicators well above expectations for its level of income per capita.

However, from the mid-1980s onwards, as a result of several factors such as the ageing population, the withdrawal of the state from the health sector, and the lower efficacy and efficiency of the health system, the gap between China and the middle income countries narrowed. Between 1990 and 2004,

This article is a synopsis of the studies carried out by the authors between 2000 and 2015. They gratefully acknowledge the support of the Centre d'études et de recherche sur le développement international (Research Centre for International Development, CERDI), UMR CNRS 6587, the Fondation pour les études et la recherche sur le développement international (Foundation for Studies and Research on International Development, FERDI), the University of Auvergne, and the Bureau des Affaires Sociales at the French Embassy in China. These studies could never have been brought to fruition without the unstinting collaboration that we have received over the whole period from the Weifang Medical University, the Weifang Health Bureau, and our exchanges with the National Health and Family Planning Commission (the equivalent in China of Ministry of Health). We are extremely grateful to them, but we are solely responsible for the views expressed in these analyses

1. World Bank, "Annual GDP Growth (\%)," http://worldbankorg/indicator/NY.GDP>MKPT.KD.ZG?locations $=C N \&$ page $=6$ (accessed on 2 September 2016).

2. $\quad 46 \%$ in 2014 . World Bank, "Rural Population (\% of Total Population)," http://worldbankorg/indicator/SP.RUR.TOTL.ZS? page=5 (accessed on 2 September 2016). 
the share of public expenditure to total health expenditure fell from $25 \%$ to $17 \%$, whereas the share of out-of-pocket expenditure by Chinese households rose from $36 \%$ to $53 \%$. (3) By studying the access to healthcare by the rural population of China over the periods' 1989-1993 and 2004-2006, based on CHNS data, we have shown that consumption by the poorest households was significantly affected by the financial burden falling on them, thereby widening the inequality gap. ${ }^{(4)}$

Being aware of this situation and the underlying discontent of the population, since 2003 the Chinese government has undertaken a deep reform of health policy and of the health system. It will take place through several successive stages, ${ }^{(5)}$ along three main axes: the development of health insurance and movement towards universal coverage (UHC), the reform of the hospital sector, and the restructuring of drug policies. Thus, one can see a willingness to improve not only the quality of care and the effectiveness of the health system, but also for several years now, and especially since 2009, its efficiency. Indeed, in many areas and at different levels of the health pyramid, the inefficiency of the system is a matter of concern, even if the concept of efficiency does not necessarily appear to be a goal unanimously shared by all the stakeholders, nor always clearly understood at the local authority level.

This article is concerned with the effects of the vast field of reforms already mentioned: health insurance in rural areas (the "New Rural Cooperative Medical System - NRCMS), hospital and pharmaceutical policies, and the resources, performance, and efficiency of the township hospitals ( $x$ iangzhen weishengyuan $\left.{ }^{(6)}\right)$. Township hospitals constitute the basic level of the Chinese healthcare system. In Chinese terminology, they form part of the first level in the health pyramid.

\section{Methodology}

Here we set out the principal methods used in the various studies to which we refer. There are some additional elements in the annexes.

\section{Samples and Data}

We have studied the consequences of the successive reforms undertaken in the rural areas of Weifang Prefecture, which is located roughly in the centre of Shandong Province, and is ranked third among Chinese provinces in terms of per capita income. The per capita GDP in Weifang Prefecture whose population is around 9.5 million residents - is estimated at $\$ 6,000$ for 2014 as compared with $\$ 7,500$ for the province as a whole. The prefecture is subdivided into 12 health districts. Our studies for the period 2000 to 2012 focused on a sample of 24 township hospitals (TH) and concerned specifically health insurance in rural areas. This was expanded later to 30 hospitals to study the effects of the new drug policy on THs. Hospitals were selected from a stratified random sample on the per capita income of the township to which they belong, following a footstep proportional to the size of the district population. The 24 hospitals initially selected are distributed across six districts; the six additional hospitals are taken from two other districts. The samples represent $14 \%$ and $17 \%$ respectively of all township hospitals in Weifang Prefecture.

Data and information were gathered over the $2000-2012$ period by using a framework drawn up by the authors, filled in by the Franco-Chinese team at the studied hospitals and at the different administrative levels of the county, township, and the corresponding NRCMS offices. Administrative data were collected at the statistics and finance offices of the townships and counties in charge of the hospitals in the study, and include general information (population size, per capita income, county area, etc.), and information relative to insurance (date of the introduction of the NRCMS, coverage rate, rate and amount of reimbursements). The data collected at the hospital level were from computerised and non-computerised hospital registers. They cover hospital resources (staff, beds, equipment, subsidies, and other financial resources) and activities (external consultations, hospitalisations, vaccinations, laboratory tests, radiology, etc.). Additional qualitative data were gathered via semi-informal face-to-face interviews, based on questionnaires, with the hospital directors and their close collaborators, as well as with the management team of the prefectural health bureaus. The aim was to get an accurate idea of the way hospitals are managed, and of how the directors and their team reacted to the different reforms, some of which had to entail severe restraints on a TH's income.

The concept of efficiency comes down to raising the question of the best use of resources to achieve a certain production by focusing either on the costs of production (allocative efficiency) or on the quantities produced or used (technical efficiency). This study focuses on technical efficiency, which is measured more precisely by the capacity to obtain maximum production (here, hospital activity) without any increase in available resources (the socalled output orientation model), or else to obtain a given level of production by using the least possible resources (input orientation model).

The technical efficiency of the township hospitals was assessed by using non-parametric Data Envelopment Analysis (DEA) to study the effects of health insurance in rural areas, and order-m ${ }^{(7)}$ partial frontier efficiency for the study of the hospital and pharmaceutical reforms. The assumption of the variable returns to scale instead of constant returns to scale is retained, as it is more relevant when the size of the hospitals and the managerial capabilities ${ }^{(8)}$ are taken into account (for further methodological details, see Annex 1).

The missions of township hospitals in China are to deliver both curative and preventive health care, for which they receive specifically allocated resources. Due to their multiple activities in both the curative and the preventive field, we computed a composite output index. Since hospitals have little room for choice over some of their resources (staffing, mainly), we opted for an output orientation approach for calculating the efficiency scores.

In order to study the effects of health insurance we have calculated two models of efficiency (one for the curative activities and the other for the preventive ones). The available data cover a fairly long period (2000-2008), marked by a progressive introduction of rural health insurance. We identified three sub-periods: 2000-2002 (before the introduction of the reforms),

3. China Health Statistics Yearbook, 2005.

4. Martine Audibert, Yong He, and Jacky Mathonnat, "Two-Period Comparisons of Healthcare Demand with Income Growth and Population Aging in Rural China: Implications for Adjustment of the Healthcare Supply and Development," Études et Documents, CERDI, No. 15, 2013.

5. Jacky Mathonnat, Martine Audibert, Xiezhe Huangfu, Anning Ma, and Laurène Petitfour, "Progrès et défis pour trois réformes majeures dans le système de santé chinois" (Progress and challenges for three major reforms in the Chinese health system), Mondes en développement, Vol. 2, No. 170, 2015, pp. 105-121.

6. The township is the first level of administration just above the village. Next comes the county (xian), then the prefecture (diqu), followed by the province (sheng). See Isabelle Thireau, "Editorial," China Perspectives, No. 2013/1, p. 6.

7. Catherine Cazals, Jean-Pierre Florens, and Léopold Simar, "Nonparametric Frontier Estimation a Robust Approach," Journal of Econometrics, No. 106, 2002, pp. 1-25.

8. Rowena Jacobs, Peter Smith, and Andrew Street, Measuring Efficiency in Healthcare, New York, Cambridge University Press, 2006. 
2003-2005 (introduction and implementation of the reforms), and 2006 2008 (consolidation). To take account of the specific nature of each subperiod, both models were assessed for each sub-period. For each TH and for each model (curative and preventive), three efficiency scores were calculated (see Annex 1).

The variables considered, the same for each of the sub-periods, are as follows:

- For the curative model:

- Output: a composite index, including outpatient visits, inpatients,

home visits, emergencies, laboratory tests, and X-ray examinations, was built using weightings (cf. Annex 2a);

- Input (resources): number of medical staff, administrative staff, available beds, and a composite equipment index, computed from the principal component analysis (PCA, cf. Annex 2b).

- For the preventive model:

- Output. a composite index, including both compulsory and noncompulsory vaccinations, was built using weightings (cf. Annex 2a); - Input: the number of medical and administrative staff assigned to these activities.

A Malmquist Index, allowing the assessment over time of the proportion of changes in efficiency resulting from changes in the technical process and from "pure" technical efficiency, was computed (cf. Annex 1).

Concerning the study of the effects of reform of hospitals and of pharmaceutical policies, an efficiency model was estimated for the period 2002 2006. The output variable is a composite index of global activity (curative and preventive), built by using the Principal Component Analysis - PCA (cf. Annex $2 \mathrm{~b}$ ). Inputs (or resources) considered are hospital staff, number of available beds, and the Composite Index of Equipment (built using PCA, cf. Annex 2b).

\section{3-2009: Development of health insurance in rural areas, and performance and efficiency of first-level health facilities}

\section{Context}

In order to compensate for their reduced resources after the withdrawal of the state from the health sector, health facilities had to resort to charging their users, if not to balance their accounts then at least to maintain a manageable level of deficit. Gradually a profit motive emerged in those establishments, leading the cost of care to rise faster than per capita income. Moreover, relying on market-inspired elements in the Chinese economic reforms led to the closure of many state enterprises and the disappearance of agricultural co-operatives in favour of the family responsibility system, which in turn brought on the collapse of the social security scheme. By the end of the 1980s, less than $5 \%$ of the rural population were covered by health insurance, against over $95 \%$ in the late 1970s. The households were faced with an expensive health system, well beyond the reach of the poorest and severely degraded in terms of quality of care, which was especially noticeable in rural areas (in village health stations as well as township hospitals). (9)

The first substantial reform initiated by the government was then to rebuild insurance coverage in the rural areas. In 2003, the new rural cooperative medical system (NRCMS), mentioned above, was progressively established. Its aim was to cover the whole of the rural population by 2009 so as to improve their health status by lowering financial barriers to healthcare access. The system is based on three principles:

- Tripartite financing: premiums paid by households, and subsidies from local governments (districts and regions) and from the central state;

- Improvements in the quality of healthcare at the first level of the healthcare system;

- Strong commitment by the central government and by local governments. The latter are responsible for implementing the directives issued from the central level for improved results, with potential important implications for the personal career prospects of those in charge of piloting the reform at the various levels of the system.

In parallel with better access to healthcare, the central government expected the reform to rationalise the care system by transferring part of the demand from the overloaded hospitals at the upper levels down to the primary level (village health stations and township hospitals).

\section{Progression of the activity}

The analysis of our data shows that the development of the NRMCs has greatly increased TH activities, both curative and preventive. ${ }^{(10)}$ The total number of outpatients in the $24 \mathrm{TH}$ in the study remained stagnant between 2000 and 2005, but rose sharply (+77\%) between 2005 and 2008, increasing from 650,000 to $1,115,000$. The same applies to inpatients, whose number was relatively stable at the beginning of the period, but more than doubled, from 25,000 to more than 50,000 after 2006, when every district had fully introduced the health insurance measures. The effect of the insurance scheme shown on these indicators was confirmed by an econometric analysis and by a double-difference impact analysis. Three indicators were selected to represent health insurance and its penetration: a binary variable to show whether health insurance was introduced in the township, the proportion of the township population covered, and the reimbursement rate of hospital care for external consultations and hospitalisations. Whichever indicator was selected, the results of the econometric analysis show that the introduction of NRCMS had a beneficial effect on the volume of activity undertaken by the hospitals. This effect was more marked for inpatients (44\%) than for external consultations (16\%). This result matches the expectations of the authorities, whose efforts on reimbursement were more focused on hospitalisations than on external consultations. The effect on outpatient visits was greater in the poor townships than in the rich ones, which is also what the authorities wished to achieve. But this difference in favour of the poor has not been observed for inpatients.

The impact analysis confirms the results of the econometric analysis and gives grounds for saying that the increased volume of activity is indeed attributable to health insurance, particularly with regard to hospitalisations and lengths of stay. Compared with the hospitals that have not yet adopted the reform measures, those located in the townships that did adopt reforms have seen their hospitalisation rate increase by $58 \%$ and the bed occupancy rate by $25 \%$.

9. Arousing strong discontent in the population: IBM Business Consulting Services, "Healthcare in China: Toward Greater Access, Efficiency and Quality," 2006, www-935.ibm.com/services/ us/imc/pdf/g510-6268-healthcare-china.pdf (accessed on 11 October 2016).

10. Martine Audibert, Xiaoxian Huang, Jacky Mathonnat, Aurore Pélissier, Ningshan Chen, and Anning $\mathrm{Ma}$, Analysis of the Effects of the New Rural Cooperative Medical Scheme on the Activity, Financing and Efficiency on a Sample of Township Hospitals in Weifang Shandong Province PR China, CERDI Report, 2011 (directed by Jacky Mathonnat). 
Graph 1 - Ratio of the number of consultations and hospitalisations to curative staff number in the township hospitals studied in Weifang Prefecture

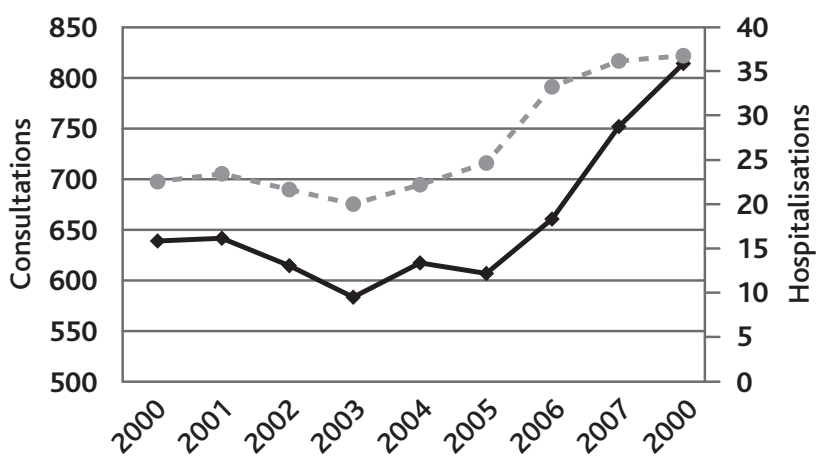

Ratio of outpatient numbers to medical staff numbers (axis on the left)

- - - Ratio of inpatient numbers to medical staff numbers (axis on the right)

Source: Authors' calculations

Graph 2 - Evolution of preventive activities in the 24 hospitals in the study

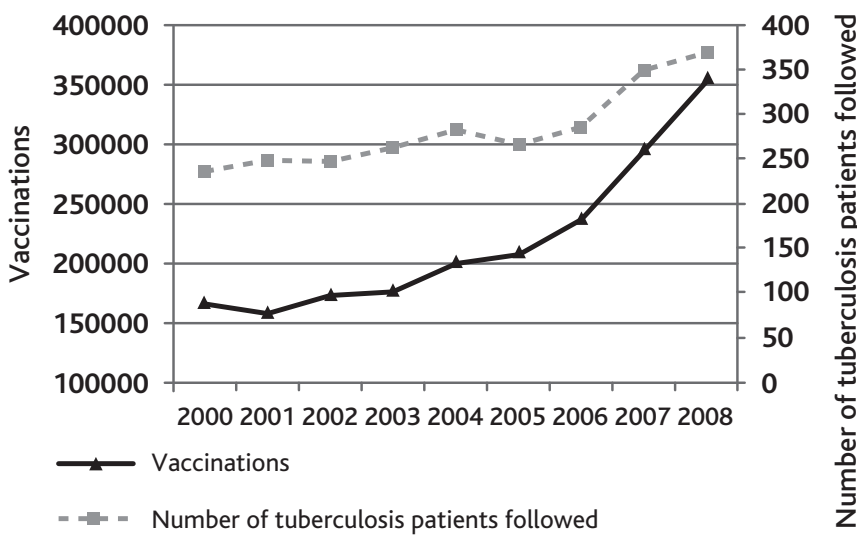

Source: Authors' calculations

The econometric analysis has also confirmed the strategic role of the authorities in the allocation of resources. One of our results concerns the negative relationship between population density and hospital activity. Our discussions with the authorities suggest that there has been a deliberate strategic policy to oversize the hospitals in the most densely populated areas in the expectation of a large increase in future demand.

The development of health insurance has had a positive effect on the hospitals' performance, measured in terms of staff productivity. There was an increase between the beginning and the end of the period under review, but it has remained weak: the productivity of the curative medical staff (leaving aside public health activities) has risen from less than three patients per day per medical staff to five (see Graph 1).

Although there was already an observed increase in preventive activity at the beginning of the period, this trend consolidated considerably after 2005, showing that the directives for public health adopted at that level of the pyramid were swiftly implemented (Graph 2). However, detailed analysis per hospital displays a mixed outcome, with some hospitals showing no change in their activities while there was a vigorous increase in activity in others. Our results are in line with those from other studies that confirm that the introduction of the new scheme health insurance has led to an overall increase in hospital activity by facilitating access to care. ${ }^{(11)}$

\section{Health insurance and hospital efficiency}

Contrary to our observations on activity, the results show that the NRCMS had no effect, or even a negative effect, on the technical efficiency of the THs, regardless of the type of activity (curative or preventive). The average efficiency score, which was already relatively low before the establishment of the NRCMS (for example, taken altogether the hospitals would have been able to increase their average curative activity by $30 \%$ and their preventive activity by $40 \%$ without additional resources), fell further with each sub-period: after the implementation of the insurance system, hospitals would have been able to increase their curative activity by an average of $50 \%$ and their preventive activity by $65 \%$ without additional resources. ${ }^{(12)}$ Moreover, as Graph 3 shows, the number of efficient hospitals fell over the period, while there was a rise in the number of relatively very inefficient ones (those with a score of less than 60\%).

It would seem that this weak performance is the outcome of financial constraints being softened by the development of the NRCMS, which allowed more resources to be allocated to the hospitals through the increase in their activity. In case of soft financial constraints, the hospital directors were not motivated to improve their management practices. The analysis of the total factor productivity (TFP, measured by the Malmquist Index) by separating, within the total technical efficiency, the amount due to the innovation from the amount due to managerial capabilities of the management team, allowed us to go deeper into the analysis. We noted that the TFP remained stable over the period 2001-2005. A detailed breakdown of this result shows that the hospitals that innovated did not seek to improve their pure technical efficiency. By contrast, those that did not innovate sought to improve their pure technical efficiency. In more concrete terms, during the pre-reform period, the total factor productivity did not change, the technical progress having rather diminished, whereas in the second period, the technical progress increased. After 2006 (the reform consolidation period), there was a stronger increase to be observed in the total factor productivity. This was mainly due to technical progress, which had increased even more rapidly. However, even though staff productivity increased, it remained low, as we have mentioned above.

\section{The successes and challenges facing health insurance in rural areas}

The main characteristics of the effects of the NRCMS that we have observed and assessed on the basis of our work in Weifang Prefecture are

11. Winnie Yip and William Hsiao, "The Chinese Health System at a Crossroads," Health Affairs, Vol. 27, No. 2, 2008, pp. 460-468; Adam Wagstaff et al., "Extending Health Insurance to the Rural Population: An Impact Evaluation of China's New Cooperative Medical Scheme," Journal of Health Economics, No. 28, 2009, pp. 1-19.

12. Aurore Pélissier, Martine Audibert, Jacky Mathonnat, Xiaoxian Huang, and Anning Ma, "Curative Activities of Township Hospitals in Weifang Prefecture, China: An Analysis of Environmental and Supply-side Determinants," Économie Publique, Vol. 28-29, No. 1-2, 2012; Martine Audibert, Jacky Mathonnat, Aurore Pélissier, Xiaoxian Huang, and Anning Ma, "Health Insurance Reform and Efficiency of Township Hospitals in Rural China: An Analysis from Survey Data," China Economic Review, Vol. 27, 2013, pp. 326-338; Martine Audibert et al., Analysis of the Effects of the New Rural Cooperative Medical Scheme on the Activity, Financing and Efficiency on a Sample of Township Hospitals in Weifang Shandong Province, PR China, op. cit. 


\section{Graph 3 - Number of hospitals per level of} efficiency scores

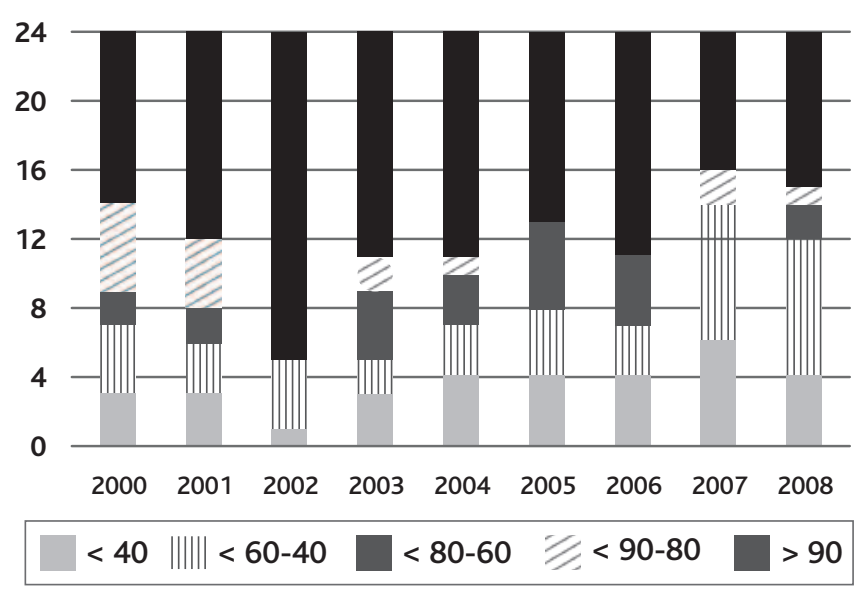

Source: Authors' calculations

largely confirmed by studies conducted in other Chinese provinces on these issues. ${ }^{(13)}$

Although these reforms have been a success in several respects, they have been less so in others. The first success, and a remarkable one, was the rapid and decisive move by households to join the NRCMS, even though joining was voluntary: ${ }^{(14)}$ from $5 \%$ coverage of households before the reforms, the rate reached $95 \%$ in 2008 . The second success was the large increase in $\mathrm{TH}$ activity, which as we have seen was an expected outcome; it raised the rate of patient contact through external consultations from 0.6 before the reforms to 0.83 afterwards.

However, not all the reform's objectives were achieved. The literature shows that insurance cover across all the rural households was not sufficient in itself to avoid catastrophic health costs and to make significant improvements in health status, as long as out-of-pocket payments fell heavily on the poor and as long as the quality of care did not show significant improvement.

The first response by the government to this situation was a steady increase in the subsidies granted to the NRCMS - from 10 yuan when they were launched, the subsidies rose to 320 yuan in 2014 - followed by a rise in the reimbursement rates and an expansion of the range of benefits. $A$ second major reform followed in 2009, namely that of the hospitals and pharmaceutical policy.

\section{9-2012: The reform of the hospitals and the pharmaceutical policy}

In 2009, the government initiated a new wave of reforms aimed at universal health coverage by 2020 . Care quality continued to preoccupy the authorities. The care provided by the township hospitals was judged to be poor by households who avoided them in favour of second-level hospitals, leading to their being overloaded. Moreover, despite the controls over the price of medicines set up between 1992 and 2007, the financial withdrawal of the state from the health sector had gradually pushed health facilities towards the profit motive, leading to widespread over-prescription and irrational use of medicine. The strategy adopted by the hospitals for bypassing the controls was to limit the use of essential fixed-price medicines (listed in 1992) in favour of medicines without price restrictions. This made these medicines more expensive for the patients and more profitable for the hospitals, which were both prescribers and suppliers. ${ }^{(15)}$

The declared aim of the 2009 pharmaceutical reform was to restrict the cost of care by acting on the price of medicines and on over-prescription. It gave rise to an expected fall in care costs borne by the patient, and an improvement in care quality. It also helped to alleviate the burden for district hospitals by encouraging a transfer of the demands on them towards the township hospitals. This was intended to improve the efficiency of the $\mathrm{TH}$, which was low as we have emphasised. But as long as the authorities do not increase resources in staff and equipment (such as beds) after the observed increase in activity that must follow the reform, the result is a greater production of services with the same resources, which will bring about a de facto improvement in efficiency.

This reform has four aspects: the production of medicines, the fixing of prices, the modalities for providing and paying for the care structures, and the rationalising of prescriptions. A new list of essential medicines has been drawn up. It came into force in 2012 and includes 317 medicines produced by the pharmaceutical industry, 203 by traditional Chinese medicine, and a certain number of plants with "recognised" medicinal properties. ${ }^{(16)}$ In order to take account of the specific needs of the different provinces, local governments may add a supplementary list. For example, in Shandong Province a further 216 medicines were added. Essential medicines are sold at cost price, ${ }^{(17)}$ because the primary healthcare facilities no longer have the right to sell them for a profit ' "zero mark-up" policy). Moreover, these medicines are the only ones that such facilities are allowed to prescribe. When care delivery specifically requires the use of non-essential medicines, the patient has to be referred to the district hospital or to buy drugs on the market. In this way the de facto link between hospital income and staff income, which had emerged because of hospitals' ability to increase their revenue through the sale of medicines without price controls, was broken once staff were no longer motivated to over-prescribe. To make up for the loss of resources linked to the sale of medicines, different mechanisms for compensation have been put in place, each district being able to choose the modality that suits it best. They are: compensation paid exclusively by government subsidies, an incentive system such as payments related to measurable results, the development of supporting activities (laboratory tests, and X-ray examinations) from which the hospital gets a share, or a mixture of several of these methods. Finally, in accordance with the desire to emphasise public health, the functions of the township hospitals were strengthened by the development of preventive activities (targets for vaccination numbers, followed by targets for children and the elderly to be given health checks and, where necessary, home visits) and more demanding supervision of health stations.

13. Kimberly Barbiaz, Grant Miller, Hongmei Yi, Linxiu Zhang, and Scott Rozelle, "New Evidence on the Impact of China's New Rural Cooperative Medical Scheme and its Implications for Rural Primary Healthcare: Multivariate Difference-in-difference Analysis," British Medical Journal, No. 341, 2010, p. 1-9; Adam Wagstaff et al.," "Extending Health Insurance to the Rural Population:An Impact Evaluation of China's New Cooperative Medical Scheme," 2009, art. cit.

14. Although it was voluntary, joining the health insurance scheme was strongly encouraged. The local health authorities undertook measures to favour the achievement of almost total coverage. For example, the Weifang health bureau cooperated with the NRCMS to organise health campaign such as free check-ups for the elderly and free detection of cardio-vascular diseases.

15. Jacky Mathonnat et al., "Progrès et défis pour trois réformes majeures dans le système de santé chinois" (Progress and challenges for three major reforms in the Chinese health system), art. cit.

16. National Health and Family Planning Commission, Guojia jiben yaowu mulu (National list of essential medicines), 2012, www.gxhfpc.gov.cn/uploads/2015/1104/20151104090153744.pdf (accessed on 13 October 2016).

17. Users pay the costs of care in advance and claim repayment later 
Graph 4 - Evolution in the distribution of the average number of overall staff in hospitals studied between 2006 and 2012

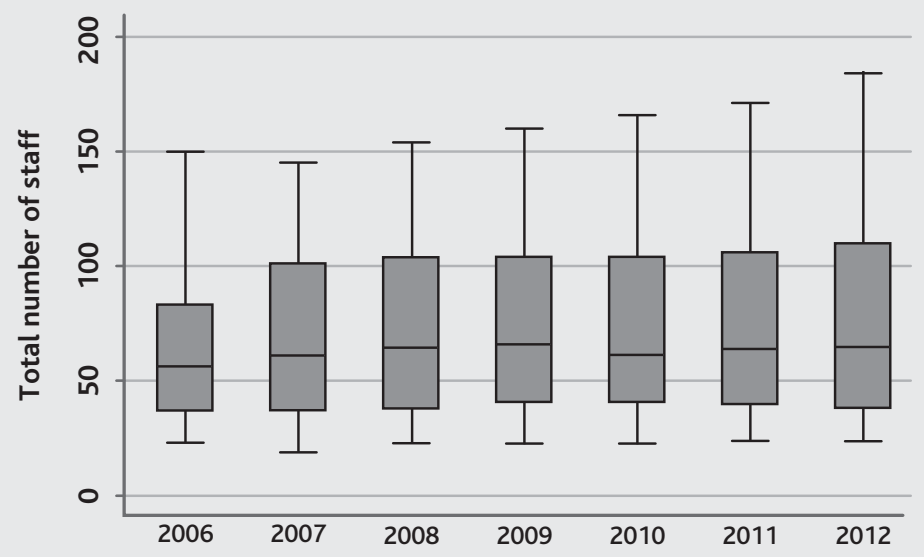

Source: Authors' calculations. Graphics using "moustachioed boxes" are useful for representing several distinct features of a distribution at the same time. The lower and upper limits of the shaded areas represent respectively the upper and lower quarters of the values in the sample, and the horizontal lines show the median. The "moustaches": the horizontal lines at the extremities of the vertical lines that prolong the shaded areas are the highest and the lowest values. The points above the moustaches (Graphs 5 and 8) are the uppermost values. This gives a good overall view of the annual distribution in the series.

\section{Graph 5 - Distribution of the number of available} (open) beds over the period studied

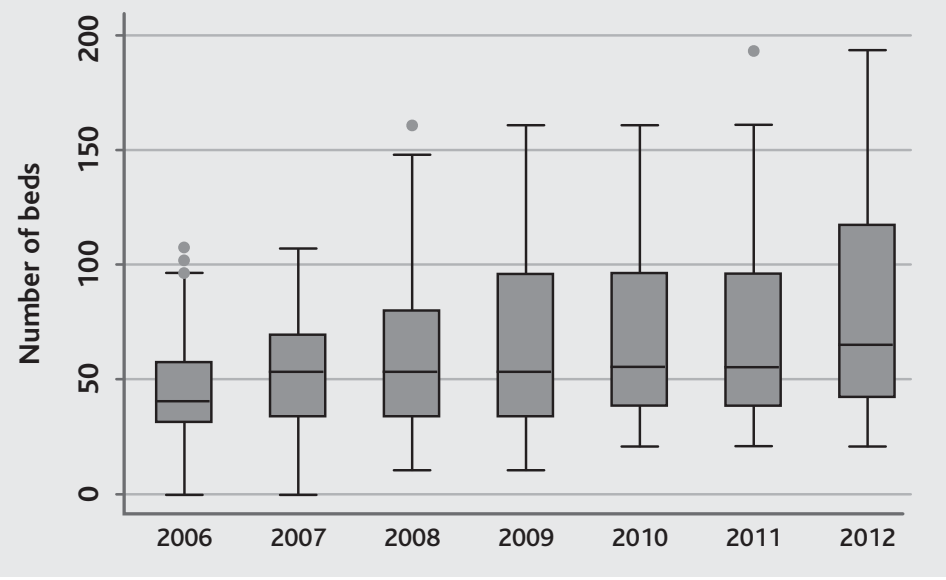

Source: Authors' calculations

\section{The strategies of the township hospitals}

Descriptive analysis of the data we gathered ${ }^{(18)}$ highlights shifts in the township hospitals' resources, both human and physical, over the period studied (2006-2012). The township hospitals' staff establishment falls into two categories: "in quota" and "extra quota." The number of staff in the quota is calculated and approved jointly by the Ministry of Human Resources and the Social Security Office at the provincial level, and salaries are paid out of the government budget. Staff outside of the quota are recruited by the hospitals, either because the quota could not be filled ${ }^{(19)}$ or because the hospitals want to recruit additional staff, and these are paid out of hospital funds. Our analyses show that overall staff numbers did increase, but more before the reforms than during them, with gaps between the different hospitals widening under the reforms (Graph 4). The analysis of this evolution in terms of staff status shows that, with some exceptions, the growing numbers of in-quota staff followed overall growth in staff numbers. The same applies to the number of beds, which rose sharply (from 44 in 2006 to 77 in 2012) (Graph 5). It should be noted that differences between hospitals increased as much in staff numbers as in the provision of beds.

One of the problems facing the central authorities is the increase, which may well be disproportionate, of hi-tech equipment in township hospitals. On the other hand, the acquisition of such equipment may be attractive to potential patients. Our interviews make clear the analytical importance of taking into account the ability or willingness of the hospitals to make investments, which are key to their technical level and to some extent to their attractiveness, as well as to performance in terms of efficiency. According to the accountancy rules in force, the value of their equipment reflects partly the value of the hospital's investment and partly its technical level. A threshold of 10,000 yuan has been set by the National Committee for Health and Family Planning (ministry of health) as the criterion that distinguishes commonly used equipment from so-called hi-tech equipment.

The average level of equipment acquisition, measured as previously by a composite index, increased throughout the period of the study, although the pace of investment slowed after the reform. This upward tendency varies according to the hospital concerned, some having reduced their investments while others increased them (Graph 6). Moreover, the average overall value of hi-tech equipment in the 30 hospitals studied more than doubled in constant value (730,200 yuan in 2006, and 1,768,600 yuan in 2012). The value of this type of equipment varies enormously from one hospital to another, and the differential between hospitals (standard deviation/average) became increasingly marked over the period.

These results, which throw light on the strategy of township hospitals, are also emphasised in other studies. ${ }^{(20)}$ Beyond medical reasons, there are financial considerations that encourage investment in hi-tech equipment whose costs are not framed.

\section{The effect of the reform on the resources and activity of the hospitals (21)}

One of the aims in establishing a list of essential medicines and in forbidding the sale of medicines for profit was to reduce the cost of care. That aim seems to have been achieved. In the hospitals studied, the income from medicines per outpatient and inpatient fell by around $50 \%$ between

18. Martine Audibert, Xiezhe Huangfu, Jacky Mathonnat, and Laurène Petitfour, The Chinese Drug Policy Reform: Analysis of the Activity and the Efficiency of Township Hospitals in the Shandong Province, CERDI Report, 2016.

19. One of the reasons brought up during our interviews is that the salaries offered by the government are not attractive enough to recruit qualified staff.

20. Karen Eggleston, Li Ling, Mengue Qingyue, Magnus Lindelow, and Adam Wagstaff, "Health Service Delivery in China: A Literature Review," Health Economics, No. 17, 2008, p. 149; Ying Chu Ng, "The Productive Efficiency of Chinese Hospitals," China Economic Review, No. 22, 2011, pp. 428-439.

21. Martine Audibert et al., The Chinese Drug Policy Reform:Analysis of the Activity and the Efficiency of Township Hospitals in Shandong Province, op. cit. 
Graph 6 - Changes in the average index for equipment between 2006 and 2012

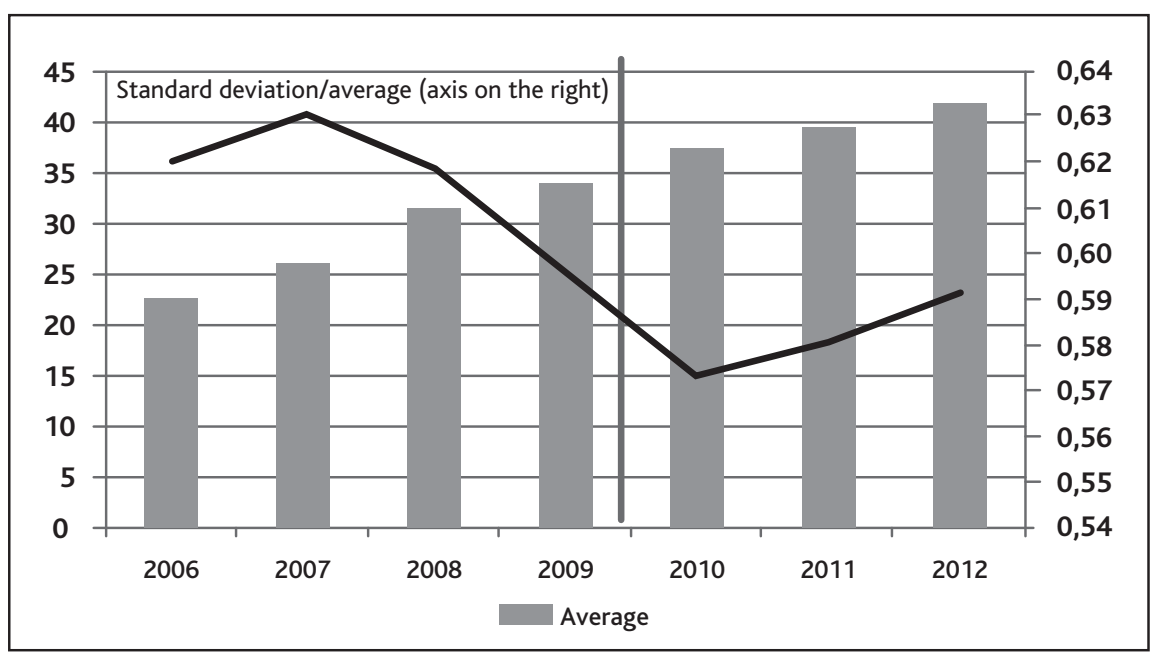

Source: Authors' calculations

2009 and 2012. This shift caused by the reform is quite clear (Graph 7). All things being equal, the result is a potential reduction in expenditure on medicine, that is to say savings (equal to a positive gain) for the patients and for the health system. We have estimated the savings at $60 \%$ of what the expenditure would have been if there had been no reform. In parallel with this, the amount of reimbursement for hospitalisation has risen greatly. In 2012 it was two to four times higher, depending on the district, than in 2008. The situation is a bit different for external consultations because there is huge range of variation according to district: in some districts the amount of reimbursement made great progress over the period, but in others it stagnated immediately after 2009

As was the case in the previous period, the curative activity (22) of the hospitals expanded greatly. The average annual number of external consultations per hospital doubled from 30,000 in 2006 to 60,000 in 2012. The number of hospital admissions likewise increased steadily in the same period, rising from an average of 1,500 per hospital in 2006 to nearly 3,400 in 2012. However, our analysis of changes in the share of admissions shows an increasing inequality between hospitals (Graph 8). One part of this growth in demand arose from the transfer of patients who, instead of being handled by the more expensive district hospitals as in the past, were now channelled more towards township hospitals. This was because of the lower cost of medicines, the better management of insurance, and the perceived (and objective) improvement in the quality of care. Another part of this increase in demand arose because some patients, who for reasons of affordability would have given up seeking health care before the reform, now became "new entrants." Finally, our interviews have revealed that village health units, having been placed directly under the township hospital authorities, are referring more patients to them.

We have seen how the hospitals could choose a form of compensation among possible options to reach a sustainable level of resources after losses due to the prohibition on selling medicines for profit. Among these options is the development of supplementary activities, such as laboratory tests, sonar tests, $\mathrm{X}$-rays, and electrocardiography. These activities developed over the period of the study, and were anticipated by increasing investment in equipment. As we noted above, the price of these activities with a relatively high technological content was not covered by the reform, and THs can make a profit in delivering the related services. This raises the question as to whether the increase in "high-tech" services is always strictly justified on medical grounds, especially as there is a significant willingness to pay for such services, and a well-known information asymmetry between care providers and patients.

\section{The effect of reform on the efficiency of the hospitals (23)}

We have seen that reform of rural health insurance did not have any clear influence on the efficiency of the hospitals. Did drug reform enable the hospitals to perform any better?

The results show that the efficiency of THs remains low. On average, they could actually improve their efficiency (that means delivering more services) by at least $40 \%$ without using more resources. Furthermore, the reform seems rather to have had a negative effect on their technical efficiency, the average of which declined over the period studied (2009-2012). In addition, a greater number of hospitals had an efficiency score equal to 60 or less (Graph 9, which likewise shows a lower average score). This is partly explained by the fact that in the greater part of the hospitals in our sample, the increase in subsidies more than made up for the loss of resources from the sale of medicine, creating what is generally called a situation of "soft budget constraint" mentioned previously. In fact, the arrangement permitting the awarding of subsidies, when compared with the previous situation, allows township hospitals to reduce their deficit, ${ }^{(24)}$ all things being equal, without having to make any particular effort to do so. It would seem, as we have emphasised already, that efforts to invest were somewhat disproportionate to needs, just as the recruitment of nonquota staff was left to the initiative of the hospitals. We also noted that some hospitals intensified the delivery of profitable activities (injections, laboratory tests, sonar scans, etc.). It is therefore quite likely that the cost of care borne by patients has fallen less than it might have done.

That said, it is not certain that this situation has restrained growth of demand in township hospitals compared to what it might have been otherwise. There is in fact a strong demand and a willingness to pay for such services, as we highlighted. If this care had not been provided by township hospitals, some of the demand would have been transferred to district hospitals. Therefore, behind the hospitals' strategic and opportunist behaviour, where it exists, there remains a central question concerning regulation, namely the lack of precise instructions for the implementation and control of evidence-based protocols. As in the previous examples, all this demonstrates that reform has not had the expected results in terms of the technical efficiency of the hospitals, which have adapted their strategies by focusing more on lucrative activities.

22. Owing to a lack of data, preventive activity, apart from vaccinations, could not be analysed. Our discussions with the hospital directors and the staff in charge of prevention suggest that the new public health initiatives are very time-consuming. It would seem that staff devote a great deal of time to keeping individual health records and making preventive home visits to deal with elderly people who are reluctant to undergo health checks when they "are not ill," and who do not turn up for their hospital appointments.

23. Laurène Petitfour, Xiezhe Huangfu, Martine Audibert, and Jacky Mathonnat, "Estimating and Explaining the Efficiency of Township Hospitals in Shandong Province in the Context of the Drug Policy Reform," Études et Documents, No. 17, 2015.

24. The majority of hospitals are in deficit every year. 
Graph 7 - Income from medicines sold through external consultations and through hospitalisation

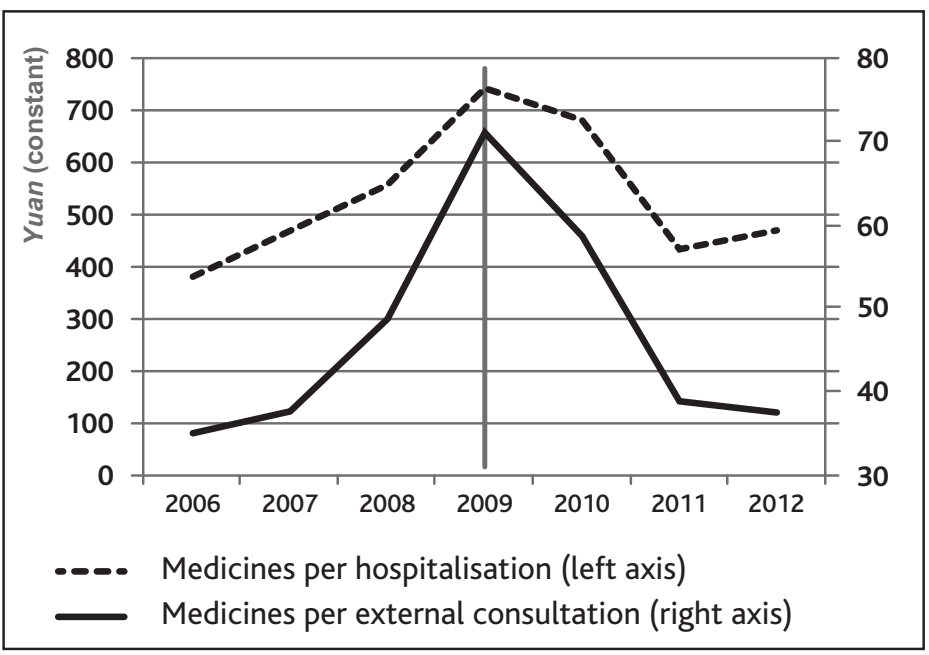

Source: Authors' calculations

\section{Conclusion}

Soon after its so-called economic liberalisation, the Chinese government found itself facing a dysfunctional health system. Having momentarily withdrawn from that system, it decided in the early 2000 s to undertake a range of reforms and to become more involved financially, particularly in linking the reforms of 2003 to health insurance in rural areas and in compensating hospitals for the loss of income imposed on them by the pharmaceutical reform of 2009.

Although the reforms have borne impressive fruits in certain respects, they have not led to the expected results in others, which continue to preoccupy the authorities.

Apart from the truly remarkable take-off of the NRCMS, which in 2015 covered about $99 \%$ of the rural population, the first positive aspect to which the two series of reforms have contributed has been to give a strong boost to the tendency emerging from the early 2000s with regard to increasing

\section{Graph 8 - Evolution and distribution of the num- ber of daily hospitalisations between 2006 and 2012 in the hospitals covered by the study}

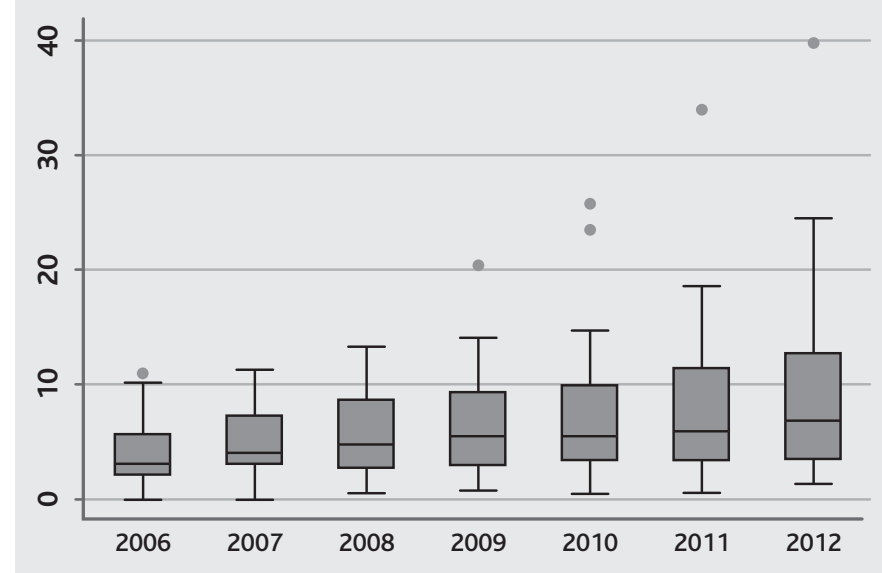

Source: Authors' calculations. To interpret this chart, see the note for Graph 6 . the activity of the township hospitals. This has put the brakes on the overloading of hospitals at the higher levels. Without these reforms - and especially, without any doubt, the insurance reform increased activity in the township hospitals would have been far lower and more heterogeneous than what we have seen.

The second positive outcome, largely due to the pharmaceutical reform (and one of its goals), has been the spectacular drop in the cost of medicines. In parallel with this, the government has agreed to a remarkable effort to compensate township hospitals for the consequent loss of income by significantly increasing the subsidies granted to them. But that very decision has encouraged, to varying extents, the moral hazard behaviour of the THs, as we have emphasised.

The third positive result is that there has been improvement in the way the NRCMS handle patients' interests: insurance reimbursements for sickness have greatly increased (rates and amounts), together with the moderating effect of the pharmaceutical policy on the cost of medicines. These latter two results have helped considerably in lowering financial barriers to access to healthcare. But the drop in the number of households facing major health expenditures ("catastrophic costs") is probably smaller than expected. A study by Wagstaff and Yu shows that in Gansu Province, households now covered by health insurance for a list of specified treatments are seeking treatments whether they are covered or not, which they would have avoided in the absence of an insurance scheme. ${ }^{(25)}$ One consequence has been an increase in private health expenditure, creating in some cases a counter-intuitive but not paradoxical link between the development of the insurance scheme and a large increase in costs borne privately by households. But there is no evidence of a nation-wide magnitude of this kind of situation.

Despite the aforementioned positive results of the reforms, however, there are still two major problems that they have not been able to resolve.

The first is the quality of health care. Admittedly, our studies do not allow us to prejudge the effect of the reforms on the quality of prescriptions or of the care delivered, because our lack of data meant that we could not take them into account. That said, however, our interlocutors tell us that care quality has actually improved with the reforms, albeit unequally. In general, major underlying problems still persist, creating major public discontent. In extreme cases, this has led to acts of violence towards medical staff in different parts of the country. ${ }^{(26)}$ It is difficult to know the extent of this problem, but it is taken very seriously by the health authorities and by the Party. Moreover, patients have become increasingly demanding and are attracted by hi-tech treatments, and this has led certain establishments to develop strategies of investment in top-of-the-range technology, enabling them to increase their income even when it is not always clear that there is any gain in care quality for the patient.

The second problem is that the efficiency of the hospitals has remained low, and even deteriorated over the final years of the study, partly because a number of them suffered from overcapacity, ${ }^{(27)}$ and partly because the

25. Adam Wagstaff and S. Yu, "Do Health Sector Reforms have their Intended Impacts? The World Bank's Health VIII Project in Gansu Province, China," Journal of Health Economics, Vol. 26, No. 3, 2005, pp. 505-535.

26. According to our interviewees at the National Health and Family Planning Commission.

27. We believe that there is a need to reconsider the health map by matching some township hospitals and reducing the size of some others. But this issue has turned out to be very sensitive. It has both an administrative dimension (complying with the current standards) and an eminently political character. 
Graph 9 - Income from medicines sold through external consultations and through hospitalisation

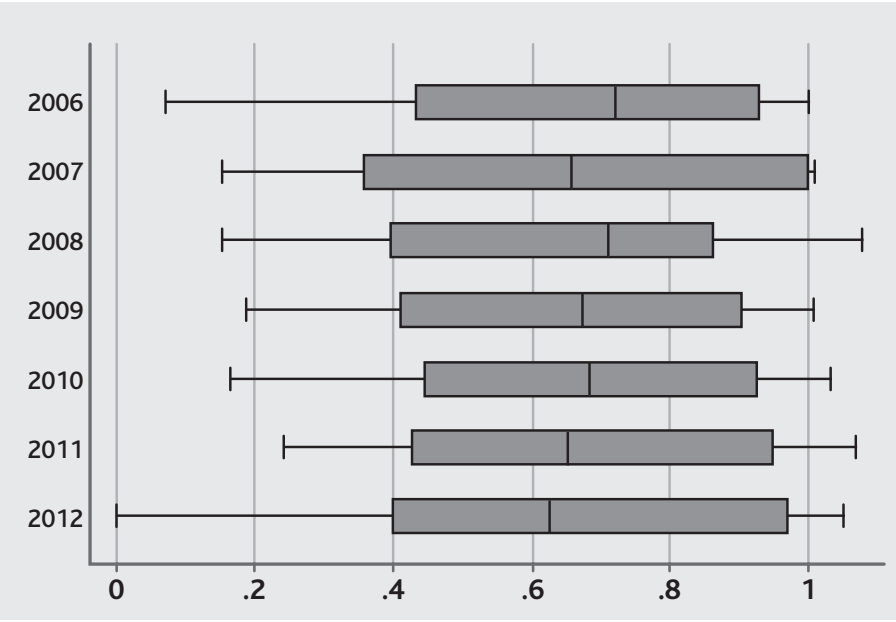

Source: Authors' calculations reforms contributed to a soft budget constraint for the THs. In addition, the system still works in a very bureaucratic manner. The managers are not really in a position to manage their establishments, and they are not sufficiently incentivised to do so. So there are questions to be asked about rearranging the incentives in order to improve efficiency, which is a very real preoccupation of the directors of the National Health and Family Planning Commission.

The authorities are well aware that these points need improvement. Over recent years some new initiatives have been launched, including the introduction of staff incentives based on results and performance criteria. Contracts specifying targets (performance) have been signed, including some with doctors in village clinics. But their incentivising character and the way they are implemented is not always very clear in the light of what we have observed. An increasing role has been also given to the private sector in order to favour some kind of regulated competition between providers. These approaches, which are going in the right direction, are directly related to the goal of improving the quality of care and the health of the population.

\section{ANNEXES}

\section{Analysing efficiency: The non-parametric approach}

Two approaches, the parametric and the non-parametric, enable the technical efficiency of the units of production to be assessed. The nonparametric approach is the one used to assess the efficiency of hospitals because, unlike the parametric, it does not presuppose any a priori specification of the form of productive function (a form that is unknown in the field of healthcare). The assessment of that function is therefore guided by the data. ${ }^{(28)}$

Among the different methods available for the assessment of efficiency, our studies have made use of two: Data Envelopment Analysis (DEA) and partial frontier analysis. Both of them are based on mathematical programming. The measure of technical efficiency is established by comparing production with the resources used. The units of production are then compared with each other. If the objective is to minimise resources, the units of production that use the least resources for a production identical to others (input orientation model) are classified as efficient and are located at the frontier of production. If the objective is to maximise production, the units of production that produce the greatest number of goods or services for a quantity of resources identical to others (output orientation model) are classified as efficient and are located at the frontier of production. The other units of production are classified as inefficient and are located beneath the frontier and at a greater or lesser distance from the frontier according to the gap between them and the efficient units. The value of the measure of efficiency (called the score) is contained between 1 (units of production that are efficient and on the frontier) and 0 (totally inefficient units of production). Every value contained between these two limits measures the distance from the unit of production to the frontier. In more concrete terms, a score of $0.7(0.4)$ shows that the unit of production could increase its output by $30 \%(60 \%)$ with the same quantity of available resources. These methods integrate equally the hypotheses of constant return to scale (when production in- creases in proportion to the variation in resources) or variable yields (when production increases more or less than proportionately to the variation in resources).

The order-m partial frontier analysis ${ }^{(29)}$ differs from the DEA method in that it assesses the efficiency by simulating several samples of $m$ units of production, comprising units that have at most the same output quantities (output orientation model) using at least the same input quantities (input orientation model). For each simulated sample, an efficiency score is assigned to each unit of production. The procedure is repeated $n$ times, then the mean score of all those simulations becomes the order-m score. This method authorises certain units of production to be above the production frontier (with a score above 1, they are considered super-efficient). When panel data are available, DEA allows the Malmquist Index to be calculated, which measures a change, between two periods, in the total productivity of the factors and allows technical progress to be isolated from pure technical efficiency. Technical progress measures a change of the frontier of production and shows that an improvement in technical efficiency is due to technological innovations rather than to management decisions, unlike pure technical efficiency, which shows that an improvement in technical efficiency is due to improved management.

\section{Constructing the composite indexes}

\section{2a. The composite activity index through the Coca method}

Hospital activity is multi-faceted, particularly in the hospitals we have studied, and it includes curative and preventive activities. The aim of the reforms is to improve the efficiency of the hospitals, but without damaging

28. Abraham Charnes, William Cooper, Arie Lewin, and Leopold Seiford, Data Envelopment Analysis: Theory, Methodology and Applications, London, Kluwer Academic Publishers, 1995.

29. Catherine Cazals, Jean-Pierre Florens, and Léopold L. Simar, "Nonparametric Frontier Estimation: A Robust Approach," Journal of Econometrics, Vol. 106, 2002, pp. 1-25. 
the functions they are expected to perform. Even if the DEA model allows us to consider a production function with several outputs, their number has to be kept to a minimum, particularly since the sample of hospitals in the study is not very large. As the strategy of hospitals varies, some of them choosing to respond to the whole of their remits while others focus on the profitable activities, it has been necessary to take all the activities into consideration. This has led us to devise two composite indexes (one for curative activities and the other for preventive activities) by recourse to calculations based on the equivalent work load, as recommended by Coca. ${ }^{(30)}$ In order to allow for local particularities, our calculations make use of the weightings proposed and discussed by a committee of Chinese experts (see Table 1 below):

\section{Table 1 - Calculation of work load equivalents}

\begin{tabular}{|c|c|}
\hline Curative Activities & Weighting \\
\hline External Consultations & 1 \\
\hline Hospitalisations & 3 \\
\hline Emergencies & 2 \\
\hline Follow-up home visits & 5.72 \\
\hline Laboratory tests & 1 \\
\hline X-ray examinations & 1 \\
\hline Preventive activities & 1.85 \\
\hline Compulsory vaccinations & 1.85 \\
\hline Other vaccinations & \\
\hline
\end{tabular}

\section{2b. Composite index with main component analysis}

When there are several variables representing a resource (equipment, for example), the question arises whether each kind of equipment should be entered into the model as separate variables or in the form of an aggregate indicator. The aggregate form is the one more usually

I Translated by Jonathan Hall.

I Martine Audibert (contact author), research director, CERDI-CNRS, Université d'Auvergne, 65, Bd. François Mitterrand, 63000 Clermont-Ferrand (martine.audibert@udamail.fr).

Xiaoxian Huang, research fellow, WHO-EPI (Extended Programme on Immunization), World Health Organization, 20 Ave Appia, $\mathrm{CH}$ 1211 Geneva 27 Switzerland (xhuang@who.int).

IXiezhe Huangfu, PhD candidate, CERDI-CNRS, Université d'Auvergne, 65, Bd. François Mitterrand, 63000 Clermont-Ferrand (huangfuxiezhe@hotmail.com).

I Jacky Mathonnat (contact author), professor, CERDI-CNRS, Université d'Auvergne, 65, Bd. François Mitterrand, 63000 Clermont-Ferrand (jacky.mathonnat@udamail.fr).

【 Aurore Pélissier, associate professor, LEDI-Université de Bourgogne, 2 bd Gabriel, F-21 066 Dijon cedex (aurore.pelissier@ubourgogne.fr). adopted in works on hospitals. Several studies estimate the value of the total equipment by adding up the monetary value of each kind of equipment. This approach has several drawbacks. Firstly, it is difficult to establish the purchase price of old equipment. Secondly, should one consider the price of such goods at the moment of the study or at the time of their purchase? Thirdly, two hospitals might find themselves in possession of an item with the same monetary value but of a different type, which might have a different effect on their activity. In fact, monetary value does not fully reflect the technological use value of a piece of medical equipment.

The principal component analysis remedies some of these drawbacks. Its aim is to reduce the number of initial variables by bringing them down to a reduced space while distorting the real situation as little as possible. Relying on an approach combining the geometrical (calculation of distances) and the statistical (matrix of variances and co-variances), it consists of generating k new variables (one or two, for example) as a linear combination of the $p$ initial variables, which leads to a minimal loss of information. These new variables are called the principal components.

\section{- The composite index of equipment}

The initial variables for the equipment taken into consideration are the number of $\mathrm{X}$-ray machines, echographers, endoscopes, and electrocardiograms in each hospital. So a new variable is then generated as an equipment index with values from 0 (for the least equipped hospital) to 100 (for the most fully equipped).

\section{- The composite index of global activity}

The activity variables taken into consideration are the number of external consultations, hospitalisations, emergencies, surgical operations, laboratory tests, vaccinations, and pre-natal consultations.

30. Elias Coca, Les inégalités entre hôpitaux: Obstacle à l'efficacité et à l'équité de la maîtrise des dépenses hospitalières (Inequalities among hospitals: An obstacle to efficiency and equity in mastering hospital expenditures), Paris, Berger-Levrault, 1995.

I Laurène Petitfour, PhD candidate, CERDI-CNRS, Université d'Auvergne, 65, Bd. François Mitterrand, 63000 Clermont-Ferrand (laurene.petitfour@udamail.fr).

Manuscript received on 28 January 2016. Accepted on 16 September 2016. 